\title{
The Murakami Cohort Study of vitamin D for the prevention of musculoskeletal and other age-related diseases: a study protocol
}

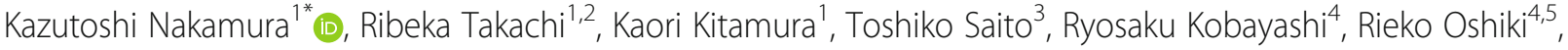 \\ Yumi Watanabe ${ }^{1}$, Keiko Kabasawa ${ }^{6}$, Akemi Takahashi $^{5}$, Shoichiro Tsugane ${ }^{7}$, Masayuki Iki $^{8}$, Ayako Sasaki ${ }^{9}$ \\ and Osamu Yamazaki ${ }^{10}$
}

\begin{abstract}
Background: Age-related musculoskeletal diseases are becoming increasingly burdensome in terms of both individual quality of life and medical cost. We intended to establish a large population-based cohort study to determine environmental, lifestyle, and genetic risk factors of musculoskeletal and other age-related diseases, and to clarify the association between vitamin D status and such diseases.

Methods: We targeted 34,802 residents aged 40-74 years living in areas of northern Niigata Prefecture, including Sekikawa Village, Awashimaura Village, and Murakami City (Murakami region). The baseline questionnaire survey, conducted between 2011 and 2013, queried respondents on their lifestyle and environmental factors (predictors), and self-reported outcomes. Plasma 25-hydroxyvitamin D (25[OH]D) concentration, an indicator of vitamin D status, was determined with the Liaison ${ }^{\oplus} 250 \mathrm{H}$ Vitamin D Total Assay. The primary outcome of this study was osteoporotic fracture; other outcomes included age-related diseases including knee osteoarthritis, perception of chronic pain, dementia, and long-term care insurance use. Mean ages of men and women were $59.2(\mathrm{SD}=9.3, \mathrm{~N}=6907)$ and $59.0(\mathrm{SD}=9.3, \mathrm{~N}=7457)$ years, respectively. From the blood samples provided by 3710 men and 4787 women, mean 25(OH)D concentrations were $56.5(\mathrm{SD}=18.4) \mathrm{nmol} / \mathrm{L}(22.6 \mathrm{ng} / \mathrm{mL})$ and $45.4(\mathrm{SD}=16.5) \mathrm{nmol} / \mathrm{L}(18.2 \mathrm{ng} / \mathrm{mL})$, respectively.

Discussion: Follow-up surveys are planned every 5 years for 15 years, and incident cases of our targeted diseases will be followed at hospitals and clinics in and nearby the cohort area. We anticipate that we will be able to clarify the association between vitamin D status and multiple disease outcomes in a Japanese population.
\end{abstract}

Keywords: Cohort studies, Dementia, Musculoskeletal diseases, Osteoporotic fractures, Vitamin D

\section{Background}

The average life expectancy in Japan is one of the highest in the world. This is attributed in part to successful prevention and treatment of fatal diseases, such as cancer, cardiovascular disease, and cerebrovascular disease. Consequently, ageing is accelerating. In 2016, 27.3\% of the population comprised elderly persons over 65 years, and that in 2055 is projected to be as high as $38.0 \%$ [1]. In such an ageing society, common age-related diseases, such as musculoskeletal diseases, become highly

\footnotetext{
* Correspondence: kazun@med.niigata-u.ac.jp

${ }^{1}$ Division of Preventive Medicine, Niigata University Graduate School of Medical and Dental Sciences, 1-757 Asahimachi-dori, Chuo-ku, Niigata 951-8510, Japan

Full list of author information is available at the end of the article
}

burdensome in terms of both individual quality of life and medical cost. For example, osteoporotic fracture and knee osteoarthritis impair physical function, leading to decreased levels of activities of daily living (ADL), and eventually to higher numbers of elderly individuals with physical disabilities requiring care. The National Livelihood Survey of the Ministry of Health, Labour and Welfare in Japan [1] reported that fractures and knee osteoarthritis account for 10.2 and $10.9 \%$, respectively, of all cases of disability requiring care, and the sum of these $(21.1 \%)$ is comparable to the percentage of individuals with cerebrovascular diseases $(21.5 \%)$ and dementia (15.3\%). Furthermore, musculoskeletal disorders are a

(c) The Author(s). 2018 Open Access This article is distributed under the terms of the Creative Commons Attribution 4.0 International License (http://creativecommons.org/licenses/by/4.0/), which permits unrestricted use, distribution, and reproduction in any medium, provided you give appropriate credit to the original author(s) and the source, provide a link to the Creative Commons license, and indicate if changes were made. The Creative Commons Public Domain Dedication waiver (http://creativecommons.org/publicdomain/zero/1.0/) applies to the data made available in this article, unless otherwise stated. 
main cause of chronic pain, which is also becoming a major public health concern [2].

The economic burden on medical insurance companies from musculoskeletal and other age-related diseases causing disability has been enormous. For example, the annual cost of treatment and after-care for hip and vertebral fractures in Japan has been estimated as 750 and 150 billion yen (nearly equivalent to 7.5 and 1.5 billion dollars), respectively [3]. Rapid increases in the economic burden on long-term care insurances are also problematic in Japan. The cost of the long-term care insurance in 2000 was 3.6 trillion yen, but had over doubled this amount, to 9.8 trillion yen in 2015 [1]. Accordingly, prevention of age-related musculoskeletal diseases is a top priority at present and in the near future.

With regard to age-related diseases, vitamin D has received increasingly more attention, as its insufficiency is considered a potential risk factor for age-related bone diseases [4] and other age-related chronic diseases, such as some cancers, vascular diseases, diabetes, and dementia $[5,6]$.Vitamin D status is also of great interest because vitamin D insufficiency is widespread worldwide [7]. Although a number of cohort studies on vitamin D status and chronic diseases have been conducted in European and North American countries, large cohort studies that target East Asian populations are lacking [8].

Over the last several years, we have conducted medium-scale epidemiologic studies on vitamin D status, osteoporosis, and osteoporotic fractures in Japanese populations and reported that higher vitamin D concentrations are associated with higher bone mass and a lower incidence of osteoporotic fractures [8, 9]. Japanese people are an interesting population in terms of vitamin $\mathrm{D}$ nutrition because they frequently eat fish, a major source of vitamin D, and consume much more fish than populations in Europe and North America [10]. This implies that some lifestyles, including dietary habits, could impact vitamin D status and bone health. Comprehensive approaches, including genetic information, should be used to determine risk factors for osteoporotic fractures.

Against this backdrop, the present study aimed to establish a large population-based cohort study to determine (1) environmental, lifestyle, and genetic risk factors of osteoporotic fractures, and their interactions; (2) factors related to other age-related diseases, including knee osteoarthritis, chronic pain, dementia, disability, and some cancers; and (3) the impact of vitamin D status on the incidence of these diseases or disorders.

\section{Methods/design \\ Participants}

The Murakami Cohort Study is a population-based study of age-related musculoskeletal diseases that targeted individuals aged between 40 and 74 years living in areas of northern Niigata Prefecture under the jurisdiction of the Murakami Public Health Centre (Murakami region). These areas include Sekikawa Village (3065 residents on April 1, 2011), Awashimaura Village (178 residents on January 1, 2011), and Murakami City (31,559 residents on January 1, 2012) (Fig. 1). All 34,802 residents in the Murakami region aged between 40 and 74 years were invited to participate in the study. Of these, 14,364 (41.3\%)

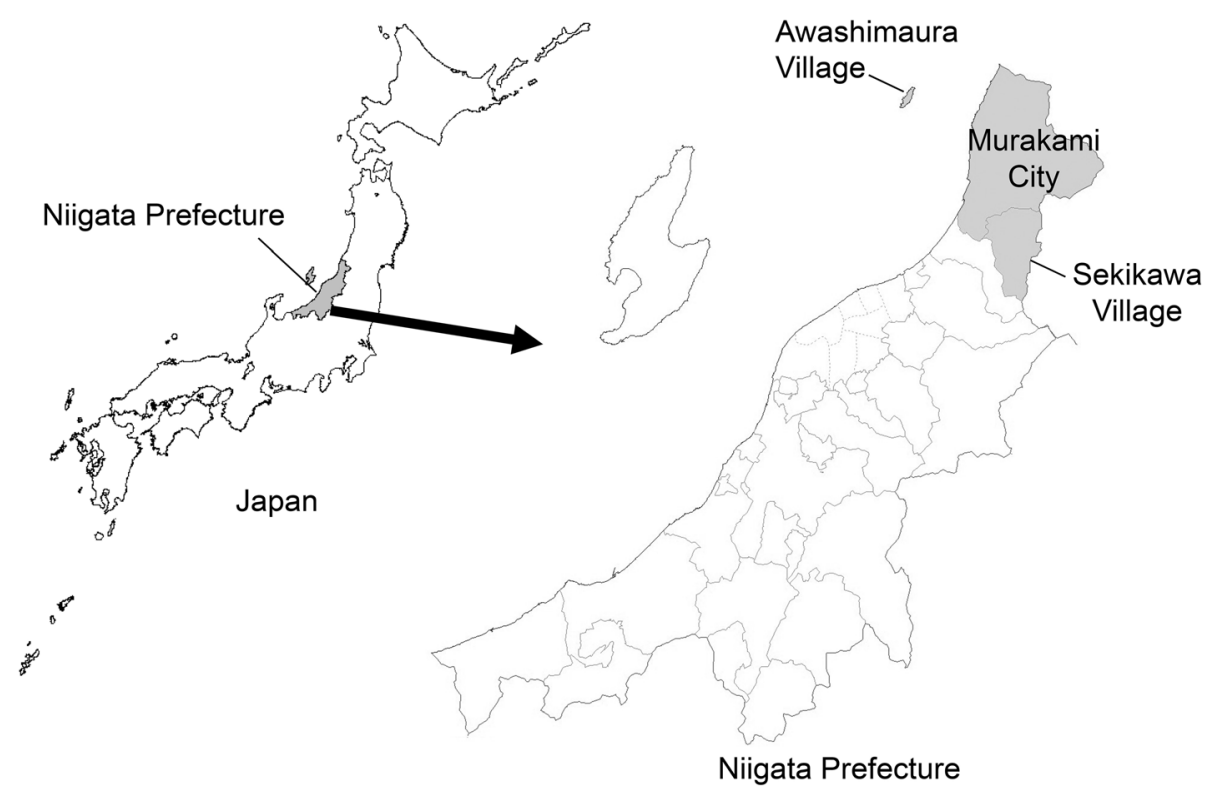

Fig. 1 Location of Murakami City, Sekikawa Village, and Awashimaura Village in Niigata Prefecture, Japan 
participated in the cohort study, and 8497 of the 14,364 participants provided blood samples. Informed consent was obtained from all participants. The protocol of this study was approved by the Ethics Committee of Niigata University School of Medicine (No. 1324 for study design and 452 and 481 for genetic analysis).

\section{Baseline study}

In the baseline survey, a self-administered questionnaire was distributed through a community-based communication network to Sekikawa residents and Awashimaura residents in early 2011 and to Murakami City residents in late 2011 and early 2012. Questionnaires were completed by those who agreed to participate in the study and collected through the network. A supplemental mail survey was used for communities where such a network is not available. At the time of the baseline survey, participants were asked to provide blood samples for future biochemical and genetic analyses. Blood sampling was performed only among those who provided consent between 2011 and early 2013 at one of the following settings: annual health check examinations provided by the local government, workplace health check examinations, local hospitals, clinics, and health care facilities of internal medicine, and an additional setting provided by our team. Blood samples were collected directly by our team, except at local hospitals, clinics, and health care facilities, where quality control of samples was ensured by respective clinical laboratories and samples were collected through BML, Inc. (Tokyo, Japan). Additional participants were recruited from annual health check examinations and workplace health check examinations between 2012 and 2013. In a subsample, clinical examination data of participants were collected from annual health check examinations provided by the local government or workplace health check examinations.

\section{Follow-up plans}

Follow-up questionnaire surveys are planned every 5 years for 15 years, with the aim to reevaluate exposures, such as lifestyles, and obtain self-reported outcomes, such as chronic pain.

Most outcome measures, e.g., incident cases of target diseases, are thoroughly be followed every year for 20 years at relevant hospitals and clinics in the Murakami region and secondary or tertiary medical centres around the Murakami region (Niigata Prefectural Shibata Hospital and Tsuruoka $\mathrm{Mu}$ nicipal Shonai Hospital). Incident cases of osteoporotic fractures and osteoarthritis are followed at hospitals and clinics involved in orthopaedics, including Murakami General Hospital, Sakamachi Hospital, Sanpoku Tokushukai Hospital,
Sasaki Orthopaedic Clinic, Takahashi Orthopaedic Clinic, and Arakawa Chuo Clinic in Murakami City, Nakajo Chuo Hospital in Tainai City, Niigata Prefectural Shibata Hospital in Shibata City, and Tsuruoka Municipal Shonai Hospital in Tsuruoka City. Certification of long-term care insurance is investigated by the local governments. Dementia cases are tracked in the abovementioned hospitals and three additional medical institutions involved in neurology, including Murakami Hamanasu Hospital, Sano Clinic in Murakami City and Kurokawa Hospital in Tainai City. Information regarding disabilities is obtained from the long-term care insurance registry of local governments. Incident cases of cancers are followed with the cancer registry of Niigata Prefecture. Mortality and moving information are obtained from residency registration and death registration according to the Basic Residential Registry Law and Family Registry Law to calculate person-years of observation, because cases of death and moving out are censored.

\section{Self-administered questionnaire}

The questionnaire was designed according to that used in the Japan Public Health Centre-based Prospective Study [11] (JPHC Study) and JPHC Study for the Next Generation (JPHC-NEXT Study) [12]. The questionnaire collected sociodemographic characteristics, family information, medical histories, body size, lifestyle, dietary intake [13]; physical and mental health (including chronic pain $[14,15])$; and reproductive history (for women only). Details are provided in Table 1. Data management procedures were carried out based on the JPHC Studies [11, 12].

We verified self-reported height and body weight using anthropometric data from health check examinations. Pearson's and Spearman's correlation coefficients between self-reported and measured data were 0.9160 and 0.9743 for male height, 0.9249 and 0.9753 for female height, 0.9490 and 0.9720 for male body weight, and 0.8737 and 0.9729 for female body weight, respectively (male $N=$ 1752, female $N=2259, P<0.0001$ for all coefficients).

\section{Baseline blood collection and examination}

Fasting or non-fasting blood specimens were drawn with EDTA-2Na-containing tubes $(7 \mathrm{~mL})$ during the day and immediately stored at $4{ }^{\circ} \mathrm{C}$ in all settings. Their plasma and buffy coat were obtained by centrifugation at $1613 \times g$ for $10 \mathrm{~min}$ in the laboratory of Niigata University Division of Preventive Medicine and stored at $-80{ }^{\circ} \mathrm{C}$ until biochemical analysis. Plasma 25-hydroxyvitamin D (25[OH]D) concentrations were determined with the Liaison ${ }^{\otimes} 25 \mathrm{OH}$ Vitamin D Total Assay (DiaSorin Inc.; Stillwater, MN, USA). Intra- and inter-assay coefficient of variation (CV) values were $3.2-8.1 \%$ and $6.9-12.7 \%$, respectively. 
Table 1 Items of the self-administered questionnaire at baseline

\begin{tabular}{|c|c|}
\hline Measures & \\
\hline \multirow[t]{6}{*}{ Sociodemographics } & Age \\
\hline & Sex \\
\hline & Marital status \\
\hline & Occupation \\
\hline & Education \\
\hline & Household income \\
\hline \multirow[t]{2}{*}{ Family information } & Family structure \\
\hline & Family disease histories \\
\hline \multirow[t]{7}{*}{ Medical history } & Fractures \\
\hline & Knee osteoarthritis \\
\hline & Cancer \\
\hline & Cardiovascular disease \\
\hline & Cerebrovascular disease \\
\hline & Other chronic diseases \\
\hline & Histories of medication use \\
\hline \multirow[t]{6}{*}{ Body size } & Current weight \\
\hline & Weight in the previous year \\
\hline & Weight at 20 years of age \\
\hline & Birth weight \\
\hline & Height \\
\hline & Waist circumference \\
\hline \multirow[t]{8}{*}{ Lifestyle } & Smoking status \\
\hline & Alcohol consumption \\
\hline & Tea and coffee consumption \\
\hline & Physical activity \\
\hline & Time spent outdoors \\
\hline & Dietary habits \\
\hline & $\begin{array}{l}\text { Dietary and nutritional intake (intakes of energy, } 53 \\
\text { nutrients, and } 29 \text { food groups) using a validated food } \\
\text { frequency questionnaire [13] }\end{array}$ \\
\hline & Sleep \\
\hline \multirow{4}{*}{$\begin{array}{l}\text { Physical and mental } \\
\text { health }\end{array}$} & Activities of daily living \\
\hline & Chronic pain* \\
\hline & General health status \\
\hline & Quality of life \\
\hline \multirow{5}{*}{$\begin{array}{l}\text { Reproductive history (for } \\
\text { women only) }\end{array}$} & Menstrual history \\
\hline & Pregnancy and birth histories \\
\hline & Breastfeeding history \\
\hline & History of hormone use \\
\hline & History of toxaemia in pregnancy \\
\hline
\end{tabular}

*Pain was evaluated using the Short Form 36 verbal rating scale $[14,15]$

For laboratory analyses at health check examinations, routine blood tests were analysed at two certified clinical laboratories of the Shibata Comprehensive Health Care Service Centre (Niigata, Japan) and BML, Inc. (Tokyo, Japan). Routine standardisation and calibration tests were conducted at these facilities.

\section{Main outcome measures}

The primary outcome of this study was osteoporotic fracture. The secondary outcomes were age-related diseases, including knee osteoarthritis, perception of chronic pain, dementia, disability (long-term care insurance use), and some cancers. Osteoporotic fracture was defined as a fracture caused by minimal trauma due to reduced bone strength [16] and typically included vertebral compression fracture, hip fracture, and other long-bone fractures. Knee osteoarthritis was diagnosed with the Kellgren-Lawrence grade scale. Chronic pain is defined as pain lasting more than 6 months [17], and its presence was determined with the self-administered questionnaire. Other outcomes included some cancers potentially involved in vitamin D status, such as colorectal and breast cancers.

\section{Future statistical plans}

Cox's proportional hazards model will be used to calculate hazard ratios (HRs) of most outcome variables in relation to levels of exposure. Regarding self-reported outcomes, including chronic pain, a logistic regression model will be used to calculate odds ratios (ORs). In the multivariate model, HRs and ORs will be adjusted for potential confounders.

\section{Sample size}

Validity of the sample size of this study should be discussed. We predict that we will observe 193,914 person-years $(14,364$ participants $\times 90 \% \times 15$ years $)$ in the 15-year follow-up. Regarding hip fracture, one of our major outcomes, 211 new cases will be observed during the 15-year follow-up (with a $90 \%$ follow-up rate), according to data from Fujiwara et al.'s 14-year cohort study on hip fracture [18]. With these constraints, we could detect relative risks of 1.7 for the highest quartile to the lowest quartile of a predictor, given an average estimated incidence of $0.016(211 /[14,364 \times 90 \%]), 80 \%$ statistical power, and $\alpha=0.05$. When limited to participants who provide blood samples $(N=8497)$, we could detect relative risks of 2.0 for the highest quartile of plasma $25(\mathrm{OH}) \mathrm{D}$, applying the same assumption. Because the incidences of the other outcomes in this study are higher than that of hip fracture, we could determine their risk factors with more statistical power.

\section{Participant characteristics}

Mean ages of men and women were $59.2(\mathrm{SD}=9.3, N=$ $6907)$ and 59.0 years $(\mathrm{SD}=9.3, N=7457)$, respectively. Demographic, physical, and lifestyle characteristics among the 14,364 participants are displayed by sex and blood sample status in Table 2. Past or current histories of self-reported musculoskeletal events or disorders are shown in Table 3. In women, prevalence of all histories 
Table 2 Characteristics (numbers) of 14,364 participants by sex and blood sample status

\begin{tabular}{|c|c|c|c|c|}
\hline \multirow[b]{2}{*}{ Characteristics } & \multicolumn{2}{|l|}{ Sex } & \multicolumn{2}{|l|}{ Blood samples } \\
\hline & Men $(N=6907)$ & Women $(N=7457)$ & Present $(N=8497)$ & Absent $(N=5867)$ \\
\hline Age group (years) & $P=0.1804$ & & $P<0.0001$ & \\
\hline$\leq 49$ & $1277(18.5 \%)$ & $1429(19.2 \%)$ & $1483(17.5 \%)$ & $1213(20.7 \%)$ \\
\hline $50-59$ & $1938(28.1 \%)$ & $2161(29.0 \%)$ & $2333(27.5 \%)$ & $1746(29.8 \%)$ \\
\hline $60-69$ & $2596(37.6 \%)$ & $2759(37.0 \%)$ & $3399(40.0 \%)$ & $1952(33.3 \%)$ \\
\hline$\geq 70$ & 1096 (15.9\%) & $1108(14.9 \%)$ & $1282(15.1 \%)$ & $956(16.3 \%)$ \\
\hline Education level & $P<0.0001$ & & $P<0.0001$ & \\
\hline Junior high school & $1889(28.2 \%)$ & $2368(32.6 \%)$ & $2330(28.0 \%)$ & $1927(34.2 \%)$ \\
\hline High school & $3597(53.6 \%)$ & $3360(46.3 \%)$ & $4258(51.1 \%)$ & $2699(47.9 \%)$ \\
\hline Junior college & $614(9.2 \%)$ & $1338(18.4 \%)$ & $1263(15.2 \%)$ & $689(12.2 \%)$ \\
\hline University or higher & $607(9.0 \%)$ & $194(2.7 \%)$ & $482(5.8 \%)$ & $319(5.7 \%)$ \\
\hline Household income (yen) & $P<0.0001$ & & $P=0.0282$ & \\
\hline $0-2,990,000$ & $2199(33.6 \%)$ & $2687(41.2 \%)$ & 1967 (38.3\%) & $2919(36.8 \%)$ \\
\hline $3,000,000-5,990,000$ & $2786(42.6 \%)$ & 2409 (36.9\%) & $1956(38.1 \%)$ & $3239(40.8 \%)$ \\
\hline $6,000,000-8,990,000$ & $1056(16.1 \%)$ & $944(14.5 \%)$ & 795 (15.5\%) & $1205(15.2 \%)$ \\
\hline $9,000,000-11,990,000$ & $305(4.7 \%)$ & $295(4.5 \%)$ & $253(4.9 \%)$ & $347(4.4 \%)$ \\
\hline$\geq 12,000,000$ & $190(2.9 \%)$ & $195(3.0 \%)$ & $160(3.1 \%)$ & $225(2.8 \%)$ \\
\hline Activities of daily living & $P=0.0455$ & & $P<0.0001$ & \\
\hline No disability & $6369(93.5 \%)$ & $6798(92.3 \%)$ & $7968(94.1 \%)$ & $5199(91.1 \%)$ \\
\hline Some disability, but able to go out alone & $399(5.9 \%)$ & $520(7.1 \%)$ & $481(5.7 \%)$ & $438(7.7 \%)$ \\
\hline Living by oneself indoors, but need help outdoors & $25(0.4 \%)$ & $26(0.4 \%)$ & $11(0.1 \%)$ & $40(0.7 \%)$ \\
\hline Need help indoors & $4(0.1 \%)$ & $2(0.0 \%)$ & $0(0.0 \%)$ & $6(0.1 \%)$ \\
\hline Bedridden & $14(0.2 \%)$ & $19(0.3 \%)$ & $6(0.1 \%)$ & $27(0.5 \%)$ \\
\hline Body mass index & $P<0.0001$ & & $P<0.0001$ & \\
\hline$<18.5$ & $206(3.0 \%)$ & $492(6.6 \%)$ & $400(4.7 \%)$ & $298(5.2 \%)$ \\
\hline $18.5-24.9$ & $4614(67.2 \%)$ & $5313(71.7 \%)$ & $6040(71.2 \%)$ & $3887(67.2 \%)$ \\
\hline $25.0-29.9$ & $1810(26.4 \%)$ & $1341(18.1 \%)$ & $1791(21.1 \%)$ & $1360(23.5 \%)$ \\
\hline$\geq 30.0$ & $233(3.4 \%)$ & $261(3.5 \%)$ & $256(3.0 \%)$ & $238(4.1 \%)$ \\
\hline Smoking (cigarettes/day) & $P<0.0001$ & & $P<0.0001$ & \\
\hline Non-smoker & $1244(18.1 \%)$ & $6335(85.5 \%)$ & $4868(57.4 \%)$ & $2711(46.8 \%)$ \\
\hline Past smoker & $3338(48.6 \%)$ & $548(7.4 \%)$ & $2312(27.3 \%)$ & $1574(27.2 \%)$ \\
\hline $1-19$ & $824(12.0 \%)$ & $394(5.3 \%)$ & $582(6.9 \%)$ & $636(11.0 \%)$ \\
\hline$\geq 20$ & $1462(21.3 \%)$ & $130(1.8 \%)$ & $721(8.5 \%)$ & $871(15.0 \%)$ \\
\hline Alcohol consumption (grams of ethanol/week) & $P<0.0001$ & & $P<0.0001$ & \\
\hline None or rarely & $1333(19.4 \%)$ & $4899(66.0 \%)$ & $3715(43.8 \%)$ & $2517(43.3 \%)$ \\
\hline $1-149$ & $1730(25.2 \%)$ & $2009(27.1 \%)$ & $2419(28.5 \%)$ & $1320(22.7 \%)$ \\
\hline 150-299 & $1335(19.4 \%)$ & $271(3.7 \%)$ & $935(11.0 \%)$ & $671(11.6 \%)$ \\
\hline $300-449$ & $1213(17.6 \%)$ & $149(2.0 \%)$ & 753 (8.9\%) & 609 (10.5\%) \\
\hline$\geq 450$ & $1265(18.4 \%)$ & $91(1.2 \%)$ & $666(7.9 \%)$ & 690 (11.9\%) \\
\hline Sex & & & $P<0.0001$ & \\
\hline Men & - & - & $3710(43.7 \%)$ & 3197 (54.5\%) \\
\hline Women & - & - & 4787 (56.3\%) & $2670(45.5 \%)$ \\
\hline
\end{tabular}

$P$ values were calculated by the $x^{2}$ test between men and women and between those with and without blood samples. Missing values are generated except for "age group" and "sex" 
Table 3 Past or current histories of self-reported musculoskeletal events or disorders in 14,364 participants by sex and age groups

\begin{tabular}{|c|c|c|c|c|c|c|c|c|c|c|}
\hline \multirow[b]{2}{*}{$\begin{array}{l}\text { Musculoskeletal } \\
\text { disorders }\end{array}$} & \multicolumn{5}{|l|}{ Men } & \multicolumn{5}{|l|}{ Women } \\
\hline & $\begin{array}{l}\leq 49 \text { years } \\
\text { old }\end{array}$ & $\begin{array}{l}\text { 50-59 years } \\
\text { old }\end{array}$ & $\begin{array}{l}\text { 60-69 years } \\
\text { old }\end{array}$ & $\begin{array}{l}\geq 70 \text { years } \\
\text { old }\end{array}$ & $\begin{array}{l}P \text { for } \\
\text { trend }\end{array}$ & $\begin{array}{l}49 \text { years } \\
\text { old }\end{array}$ & $\begin{array}{l}\text { 50-59 years } \\
\text { old }\end{array}$ & $\begin{array}{l}\text { 60-69 years } \\
\text { old }\end{array}$ & $\begin{array}{l}\geq 70 \text { years } \\
\text { old }\end{array}$ & $\begin{array}{l}P \text { for } \\
\text { trend }\end{array}$ \\
\hline \multicolumn{11}{|c|}{ Past history of fracture* ${ }^{*}$} \\
\hline \multirow[t]{2}{*}{ Lumbar region } & $3 / 1272$ & $4 / 1933$ & $12 / 2593$ & 12/1093 & 0.0018 & $1 / 1423$ & $4 / 2154$ & $12 / 2752$ & $9 / 1102$ & 0.0011 \\
\hline & $(0.2 \%)$ & $(0.2 \%)$ & $(0.5 \%)$ & $(1.1 \%)$ & & $(0.1 \%)$ & $(0.2 \%)$ & $(0.4 \%)$ & $(0.8 \%)$ & \\
\hline \multirow[t]{2}{*}{ Forearm } & $37 / 1272$ & 71/1933 & $76 / 2593$ & 22/1093 & 0.1107 & $20 / 1423$ & $35 / 2154$ & $89 / 2752$ & $51 / 1102$ & $<0.0001$ \\
\hline & $(2.9 \%)$ & $(3.7 \%)$ & $(2.9 \%)$ & $(2.0 \%)$ & & $(1.4 \%)$ & $(1.6 \%)$ & $(3.2 \%)$ & $(4.6 \%)$ & \\
\hline \multirow[t]{2}{*}{ Hip } & $6 / 1272$ & $6 / 1933$ & $5 / 2593$ & 4/1093 & 0.4062 & $0 / 1423$ & $1 / 2154$ & $5 / 2752$ & 3/1102 & 0.0272 \\
\hline & $(0.5 \%)$ & $(0.3 \%)$ & $(0.2 \%)$ & $(0.4 \%)$ & & $(0.0 \%)$ & $(0.0 \%)$ & $(0.2 \%)$ & $(0.3 \%)$ & \\
\hline \multirow[t]{2}{*}{ Past history of fall ${ }^{\dagger}$} & $272 / 1234$ & $368 / 1875$ & $496 / 2535$ & $248 / 1064$ & 0.6960 & 212/1395 & $383 / 2114$ & $497 / 2700$ & $244 / 1072$ & $<0.0001$ \\
\hline & $(22.0 \%)$ & $(19.6 \%)$ & $(19.6 \%)$ & (23.3\%) & & $(15.2 \%)$ & $(18.1 \%)$ & $(18.4 \%)$ & $(22.8 \%)$ & \\
\hline \multirow{2}{*}{$\begin{array}{l}\text { Current knee } \\
\text { osteoarthritis }\end{array}$} & $13 / 1265$ & $52 / 1913$ & $204 / 2576$ & 131/1078 & $<0.0001$ & $31 / 1417$ & $158 / 2145$ & $397 / 2735$ & 273/1091 & $<0.0001$ \\
\hline & $(1.0 \%)$ & $(2.7 \%)$ & $(7.9 \%)$ & (12.2\%) & & $(2.2 \%)$ & $(7.4 \%)$ & (14.5\%) & (25.0\%) & \\
\hline \multirow{2}{*}{$\begin{array}{l}\text { Current chronic } \\
\text { pain }^{\ddagger}\end{array}$} & $389 / 1265$ & $631 / 1913$ & $988 / 2576$ & $436 / 1078$ & $<0.0001$ & $442 / 1417$ & $782 / 2145$ & $1107 / 2735$ & $527 / 1091$ & $<0.0001$ \\
\hline & $(30.8 \%)$ & (33.0\%) & (38.4\%) & (40.5\%) & & (31.2\%) & (36.5\%) & $(40.5 \%)$ & (48.3\%) & \\
\hline
\end{tabular}

*Subjects were asked to report fractures that were not caused by high energy trauma, such as a motor vehicle accident, fall from a higher level than a standing height, or occupational accident

${ }^{\dagger}$ Subjects were asked to report falls from a standing height or less

${ }^{\ddagger}$ Subjects were asked to report pain lasting for more than 6 months in any part of the body

increased significantly with age. In men, prevalence of history of spinal fracture, knee osteoarthritis, and chronic pain increased significantly with age, but prevalence of histories of forearm and hip fractures and fall did not. The mean plasma 25(OH)D concentration in all participants who provided blood samples was $50.3 \mathrm{nmol} / \mathrm{L} \quad(\mathrm{SD}=18.2, \quad N=8497)$. Mean plasma $25(\mathrm{OH}) \mathrm{D}$ concentrations by sex, age group, and season of blood collection are shown in Table 4. Health check examination data by sex $(N=4014)$ are shown in Table 5.

\section{Discussion}

A number of population-based cohort studies to determine risk factors for osteoporotic fracture have been conducted in European and North American countries [19]. Among them, large-scale studies $(n>5000)$ include the CaMos $(N=5143, \geq 25$ years old) [20], EPIC-Norfolk $(N=14,824,42-82$ years old) [21], EPIDOS $(N=7598, \geq$ 75 years old) [22], OSTPRE $(N=12,191,47-56$ years old) [23], PERF ( $N=5564,45-70$ years old) [24], Rotterdam $(N=14,926, \geq 45$ years old $)[25]$, and SOF $(N=$ $9516, \geq 65$ years old) [26] studies. In Japan, the Fujiwara-kyo Study ( $N=4427, \geq 65$ years old) [27] is an ongoing cohort study on osteoporotic fractures. The Murakami Cohort Study is considered one of the largest studies on osteoporotic fractures, comparable to previous studies.

We have established a population-based cohort study on musculoskeletal and other age-related diseases with a sufficient sample size and plan to follow our population for
15 years. We anticipate that we will be able to clarify the association between vitamin $\mathrm{D}$ status and multiple disease outcomes in a Japanese population. The present study is one of the largest cohort studies to clarify the effects of vitamin $\mathrm{D}$ in an Asian population. One strength of this cohort study is related to the geographical features of the Murakami region. As it is surrounded by mountains and

Table 4 Mean plasma 25-hydroxyvitamin D concentrations and standard deviations (SDs) by sex, age group, and season in 8497 participants providing blood samples

\begin{tabular}{llllll}
\hline & & \multicolumn{2}{l}{25 -hydroxyvitamin D (nmol/L) } & \\
& $N$ & Mean & SD & $P$ value* \\
\hline Sex & 3710 & 56.5 & 18.4 & $<0.0001$ \\
$\quad$ Men & 4787 & 45.4 & 16.5 & \\
$\quad$ Women & & & & Reference \\
Age group (years) & 1489 & 42.9 & 17.6 & $<0.0001$ \\
$\quad<49$ & 2345 & 47.7 & 17.7 & $<0.0001$ \\
$50-59$ & 3400 & 53.7 & 17.9 & $<0.0001$ \\
60-69 & 1263 & 54.5 & 17.0 &
\end{tabular}

Season of blood collection

\begin{tabular}{lllll} 
Spring (Mar-May) & 1905 & 44.9 & 17.4 & Reference \\
Summer (Jun-Aug) & 3890 & 50.8 & 17.6 & $<0.0001$ \\
Autumn (Sep-Nov) & 2375 & 53.9 & 18.6 & $<0.0001$ \\
Winter (Dec-Feb) & 327 & 48.8 & 19.5 & 0.0047 \\
\hline
\end{tabular}

Multiply the values by 0.4 to convert $\mathrm{nmol} / \mathrm{L}$ to $\mathrm{ng} / \mathrm{mL}$ for 25-hydroxyvitamin $D$

${ }^{*} T$ test was used to analyse sex, and Dunnett's test was used for the other variables 
Table 5 Results of health check examinations $(N=4014)$

\begin{tabular}{|c|c|c|c|c|}
\hline \multirow[b]{2}{*}{ Characteristics } & \multicolumn{2}{|l|}{ Men } & \multicolumn{2}{|c|}{ Women } \\
\hline & $\bar{N}$ & Mean (SD) & $\bar{N}$ & Mean (SD) \\
\hline Body mass index $\left(\mathrm{kg} / \mathrm{m}^{2}\right)$ & 1753 & $23.6(3.1)$ & 2261 & $22.6(3.3)$ \\
\hline Waist circumference (cm) & 1695 & $84.7(8.5)$ & 2237 & $80.5(9.1)$ \\
\hline Systolic blood pressure (mmHg) & 1753 & $129.6(17.3)$ & 2261 & $123.5(16.8)$ \\
\hline Diastolic blood pressure $(\mathrm{mmHg})$ & 1753 & $79.3(10.7)$ & 2261 & $73(10.3)$ \\
\hline Serum HDL cholesterol (mg/dL) & 1712 & $56(14.7)$ & 2247 & $63.7(14.5)$ \\
\hline Serum LDL cholesterol (mg/dL) & 1712 & $109.4(28.7)$ & 2247 & $118.5(27.4)$ \\
\hline Serum triglyceride $(\mathrm{mg} / \mathrm{dL})$ & 1712 & $151.1(117.5)$ & 2247 & $114.8(73.4)$ \\
\hline Serum ALT (U/L) & 1712 & $24.5(13.9)$ & 2247 & $18.6(10)$ \\
\hline Serum AST (U/L) & 1712 & $26.4(11.9)$ & 2247 & $22.3(7)$ \\
\hline Serum $\gamma$-GTP $(U / L)$ & 1712 & $49.6(64.8)$ & 2247 & $21.3(19.5)$ \\
\hline Blood sugar (mg/dL) & 1474 & $112.2(31.6)$ & 1820 & $104.3(26.8)$ \\
\hline Blood HbA1c (\%) & 1441 & $5.7(0.6)$ & 1870 & $5.6(0.4)$ \\
\hline Blood haemoglobin (g/dL) & 1691 & $14.5(1.3)$ & 2018 & $12.9(1.2)$ \\
\hline Red blood cell count & 1691 & $463(42)$ & 2018 & $433(35)$ \\
\hline
\end{tabular}

ALT alanine aminotransferase, AST aspartate aminotransferase, $\gamma$-GTP gamma-glutamyltransferase, HbA1c glycated haemoglobin

sea, this region has high rates of self-sufficient medical care, namely, its self-sufficient rates for the three fatal diseases in Murakami City have been reported to be $68.5 \%$ for cancer, 91.1\% for cerebrovascular disease, $80.8 \%$ for cardiovascular disease, and $81.4 \%$ for a total of the three diseases [28]. Self-sufficiency for medical care of unfatal diseases, such as musculoskeletal diseases, is considered to be equal to or higher than that for fatal diseases. Therefore, we should be able to identify most cases of our targeted diseases.

This study has some potential limitations. First, although a large number of people participated, the participation rate was not very high $(41.3 \%)$. In addition, no information on medication use was collected from participants. Therefore, our results may not accurately reflect the entire population of the study area. Second, generalisation of our results should be made with caution. The Murakami region includes medium- and small-sized local governments. Therefore, while our results can be generalised to regions with similar-sized populations, they may not apply to regions with larger local governments or metropolitan governments (e.g., Tokyo). Moreover, lifestyles differ between the Murakami region and metropolitan regions. For instance, many elderly living in medium or small communities in Japan retain old, traditional lifestyles, which also include particular dietary habits. Finally, in some fracture studies, bone mineral density (BMD) is measured to evaluate individual bone mass, because low BMD, i.e., osteopenia or osteoporosis, is established as a clinical risk factor for osteoporotic fracture. For this reason, the present study does not contribute to the prevention of osteoporosis or to the secondary prevention of osteoporotic fracture.
Abbreviations

25(OH)D: 25-Hydroxyvitamin D; ALT: Alanine aminotransferase; AST: Aspartate aminotransferase; BMD: Bone mineral density; CaMos: Canadian Multicentre Osteoporosis Study; CV: Coefficient of variation; EDTA-

2Na: Ethylenediaminetetraacetic acid disodium salt,2-hydrate; EPIC-

Norfolk: Norfolk cohort of the European Prospective Investigation into Cancer; EPIDOS: EPIDemiologie de l'OStéoporose; HbA1c: Glycated haemoglobin;

HDL: High-density lipoprotein; HR: Hazard ratio; JPHC Study: Japan Public Health Centre-based Prospective Study; LDL: Low-density lipoprotein; OR: Odds ratio; OSTPRE: Osteoporosis Risk Factor and Prevention; PERF: Prospective

Epidemiological Risk Factors; SD: Standard deviation; SOF: Study of Osteoporotic Fractures; $\gamma$-GTP: Gamma-glutamyltransferase

\section{Acknowledgements}

We are indebted to Kyowa Medex Co., Ltd. and DiaSorin Inc. for the plasma 25(OH)D assay. We also thank the following institutions for their help in blood collection: Murakami Public Health Center (Niigata Prefecture), Murakami City Government, Sekikawa Village Government, Awashimaura Village Government, the Medical Association of Murakami City and Iwafune District, Murakami General Hospital, Niigata Prefectural Sakamachi Hospital, Sampoku Tokushukai Hospital, Murakami Memorial Hospital, Senami Hospital, Sakanamachi Hospital, Aoki Clinic, Arakawa Chuo Clinic, Anzai Clinic, Hatori Clinic, Homma Clinic, Iga Clinic, Otabe Clinic, Sakura Clinic of Internal Medicine, Sano Clinic, Sato Clinic, Sato Clinic of Internal Medicine, Sato Clinic of Internal Medicine and Pediatrics, Sawada Clinic, Sega Clinic, Sekikawa Medical Office, Suzuki Clinic (Murakami City), Suzuki Clinic (Tainai City), Shibata Comprehensive Health Care Service Centre, Kenko-Igaku-Yobo-Kyokai, Niigata Association of Occupational Health, Niigata Health Care Association, BML, Inc., and Kotobiken Medical Laboratories, Inc.

\section{Funding}

This work was supported in part by JSPS KAKENHI Grants (Nos. JP23249035, JP40339958, and JP16K09078) and the National Cancer Center Research and Development Fund (23-A31 [toku] and 26-A-2). The funders have no role in the study design, including collection, management, analysis, and interpretation of data; writing of the report; or the decision to submit the report for publication.

\section{Availability of data and materials}

The datasets generated and/or analysed during the current study are not publicly available because all study participants did not consent to have their data provided to anyone outside of the research group. However, a minimal 
dataset may be available upon ethical approval by the Ethics Committee of Niigata University.

\section{Authors' contributions}

KN conceived and designed the study. RT, KK, TS, RK, RO, ST, MI, AS, and OY participated in the study design. KN, KK, YW, KK, and AT drafted the manuscript. All authors approved the final version of the manuscript.

\section{Authors' information}

Murakami Cohort Study home page: http://www.med.niigata-u.ac.jp/hyg/ murakami/index.html.

\section{Ethics approval and consent to participate}

Informed consent was obtained from all participants. The protocol of this study was approved by the Ethics Committee of Niigata University School of Medicine (No. 1324 for study design and 452 and 481 for genetic analysis).

\section{Competing interests}

The authors declare that they have no competing interests.

\section{Publisher's Note}

Springer Nature remains neutral with regard to jurisdictional claims in published maps and institutional affiliations.

\section{Author details}

'Division of Preventive Medicine, Niigata University Graduate School of Medical and Dental Sciences, 1-757 Asahimachi-dori, Chuo-ku, Niigata 951-8510, Japan. Department of Food Science and Nutrition, Nara Women's University Graduate School of Humanities and Sciences, Kitauoyahigashimachi, Nara 630-8506, Japan. ${ }^{3}$ Department of Health and Nutrition, Niigata University of Health and Welfare, 1398 Shimami-cho, Kita-ku, Niigata 951-3198, Japan. ${ }^{4}$ Department of Physical Therapy, Niigata University of Health and Welfare, 1398 Shimami-cho, Kita-ku, Niigata 951-3198, Japan. ${ }^{5}$ Department of Rehabilitation, Niigata University of Rehabilitation, 2-16 Kaminoyama, Murakami, Niigata 958-0053, Japan. ${ }^{6}$ Department of Health Promotion Medicine, Niigata University Graduate School of Medical and Dental Sciences, 1-757 Asahimachi-dori, Chuo-ku, Niigata 951-8510, Japan. ${ }^{7}$ Center for Public Health Sciences, National Cancer Center, 5-1-1 Tsukiji, Chuo-ku, Tokyo 104-0045, Japan. ${ }^{8}$ Department of Public Health, Kindai University Faculty of Medicine, 377-2 Oonohigashi, Osaka-Sayama, Osaka 589-8511, Japan. ${ }^{9}$ Murakami Public Health Center, 10-15 Sakanamachi, Murakami, Niigata 958-0864, Japan. ${ }^{10}$ Niigata Prefectural Office, 4-1 Shinkocho, Chuo-ku, Niigata 950-0965, Japan.

Received: 28 April 2018 Accepted: 1 June 2018

\section{Published online: 26 June 2018}

\section{References}

1. Health, Labour and Welfare Statistics Association. Kokumin-Eisei-no-Doko. Tokyo: Health, Labour and Welfare Statistics Association; 2017. (in Japanese).

2. Fayaz A, Croft P, Langford RM, Donaldson LJ, Jones GT. Prevalence of chronic pain in the UK: a systematic review and meta-analysis of population studies. BMJ Open. 2016;6:e010364.

3. Harada A, Matsui Y, Takemura M, Ito Z, Wakao N, Ota T. Cost-utility analysis of osteoporosis. Jpn J Geriat. 2005;42:596-608. (in Japanese)

4. Eastell R, Riggs BL. Vitamin D and osteoporosis. In: Feldman D, Pike JW, Glorieux FH, editors. Vitamin D, vol. 2. 2nd ed. Burlington: Elsevier Academic Press; 2005. p. 1101-20.

5. Holick MF, Chen TC. Vitamin D deficiency: a worldwide problem with health consequences. Am J Clin Nutr. 2008:87:1080S-6S.

6. Sommer I, Griebler U, Kien C, Auer S, Klerings I, Hammer R, et al. Vitamin D deficiency as a risk factor for dementia: a systematic review and metaanalysis. BMC Geriatr. 2017;17:16.

7. Mithal A, Wahl DA, Bonjour JP, Burckhardt P, Dawson-Hughes B, Eisman JA, et al. Global vitamin D status and determinants of hypovitaminosis D. Osteoporos Int. 2009;20:1807-20.

8. Nakamura K, Saito T, Oyama M, Oshiki R, Kobayashi R, Nishiwaki T, et al. Vitamin D sufficiency is associated with low incidence of limb and vertebral fractures in community-dwelling elderly Japanese women: the Muramatsu Study. Osteoporos Int. 2011;22:97-103.
9. Nakamura K, Tsugawa N, Saito T, Ishikawa M, Tsuchiya Y, Hyodo K, et al. Vitamin D status, bone mass, and bone metabolism in home-dwelling postmenopausal Japanese women: Yokogoshi Study. Bone. 2008;42:271-7.

10. Nakamura K, Nashimoto M, Hori Y, Yamamoto M. Serum 25-hydroxyvitamin $\mathrm{D}$ concentrations and related dietary factors in peri- and postmenopausal Japanese women. Am J Clin Nutr. 2000;71:1161-5.

11. Tsugane S, Sawada N. The JPHC study: design and some findings on the typical Japanese diet. Jpn J Clin Oncol. 2014;44:777-82.

12. JPHC-NEXT Study. http://epi.ncc.go.jp/jphcnext/. Accessed 1 Dec 2017. (in Japanese).

13. Yokoyama Y, Takachi R, Ishihara J, Ishii Y, Sasazuki S, Sawada N, et al. Validity of short and long self-administered food frequency questionnaires in ranking dietary intake in middle-aged and elderly Japanese in the Japan Public Health Center-Based Prospective Study for the Next Generation (JPHC-NEXT) protocol area. J Epidemiol. 2016:26:420-32.

14. Ware JE, Gandek B, IQOLA project group. The SF-36 health survey: development and use in mental health research and IQOLA project. Int J Ment Health 1994;23:49-73.

15. Fukuhara S, Bito S, Green J, Hsiao A, Kurokawa K. Translation, adaptation, and validation of the SF-36 Health Survey for use in Japan. J Clin Epidemiol. 1998:51:1037-44.

16. Marcus R, Dempster DW, Bouxsein ML. The nature of osteoporosis. In: Marcus R, Feldman D, Dempster DW, Luckey M, Cauley JA, editors. Osteoporosis, vol. 1. 4th ed. Oxford: Academic Press; 2013. p. 21-30.

17. Eriksen J, Ekholm O, Sjøgren P, Rasmussen NK. Development of and recovery from long-term pain. A 6-year follow-up study of a cross-section of the adult Danish population. Pain. 2004;108:154-62.

18. Fujiwara S, Kasagi F, Yamada M, Kodama K. Risk factors for hip fracture in a Japanese cohort. J Bone Miner Res. 1997;12:998-1004.

19. Johansson H, Kanis JA, Odén A, McCloskey E, Chapurlat RD, Christiansen C, et al. A meta-analysis of the association of fracture risk and body mass index in women. J Bone Miner Res. 2014;29:223-33.

20. Papaioannou A, Joseph $L$, loannidis G, Berger C, Anastassiades T, Brown JP, et al. Risk factors associated with incident clinical vertebral and nonvertebral fractures in postmenopausal women: the Canadian Multicentre Osteoporosis Study (CaMos). Osteoporos Int. 2005;16:568-78.

21. Khaw KT, Reeve J, Luben R, Bingham S, Welch A, Wareham N, et al. Prediction of total and hip fracture risk in men and women by quantitative ultrasound of the calcaneus: EPIC-Norfolk prospective population study. Lancet. 2004;363:197-202.

22. Schott AM, Cormier C, Hans D, Favier F, Hausherr E, Dargent-Molina P, et al. How hip and whole-body bone mineral density predict hip fracture in elderly women: the EPIDOS Prospective Study. Osteoporos Int. 1998;8:247-54.

23. Honkanen $\mathrm{R}$, Tuppurainen M, Kröger H, Alhava E, Saarikoski S. Relationships between risk factors and fractures differ by type of fracture: a population-based study of 12,192 perimenopausal women. Osteoporos Int. 1998:8:25-31.

24. Bagger YZ, Tankó LB, Alexandersen P, Hansen HB, Qin G, Christiansen C. The long-term predictive value of bone mineral density measurements for fracture risk is independent of the site of measurement and the age at diagnosis: results from the Prospective Epidemiological Risk Factors study. Osteoporos Int. 2006;17:471-7.

25. Hofman A, van Duijn CM, Franco OH, Ikram MA, Janssen HL, Klaver CC, et al The Rotterdam Study: 2012 objectives and design update. Eur J Epidemiol. 2011;26:657-86

26. Cummings SR, Nevitt MC, Browner WS, Stone K, Fox KM, Ensrud KE, et al. Risk factors for hip fracture in white women. Study of Osteoporotic Fractures Research Group. N Engl J Med. 1995:332:767-73.

27. Iki M, Fujita Y, Tamaki J, Kouda K, Yura A, Kadowaki E, et al. Design and baseline characteristics of a prospective cohort study for determinants of osteoporotic fracture in community-dwelling elderly Japanese men: the Fujiwara-kyo osteoporosis risk in men (FORMEN) study. BMC Musculoskelet Disord. 2009;10:165

28. Yamazaki O. Evaluation of a trial of setting region for secondary medical care area based on the utilization for three major diseases in Niigata Prefecture. Niigata Med J. 2009:123:160-9. (in Japanese) 